Egyptian Poultry Science Journal

http://www.epsaegypt.com

ISSN: 1110-5623 (Print) - 2090-0570 (On line)

\title{
Effects of dietary bee pollen and mannan oligosaccharide on semen quality in rabbits under Egyptian summer conditions
}

\author{
By
}

\section{H.S. Zeweil, S. M. Zahran, M. H. Abd-El-Rahman, Yassmine M. El-Gindy and M. M. Gebril}

Dep. of Anim. and Fish Prod., Facu. of Agric. (Saba Basha), Univ. of Alexandria, Alexandria, Egypt

Corresponding author: M. M. Gebril; E-mail: alhasym@gmail.com

Received:20/10/2016 Accepted:06/11/2016

\begin{abstract}
The objectives of the present study were to verify the effect of using bee pollen and mannan oligosaccharide (MOS) in the feed mixture on semen quality and reduce the effect of lipid peroxidation of V-line rabbit buck semen during Egyptian hot summer season. A total number of 16 mature $\mathrm{V}$ line (VL) rabbit bucks 7-8 months-old of proven fertility with an average initial live body weight of $3.52 \pm 0.32 \mathrm{~kg}$ were classified into four homogeneous

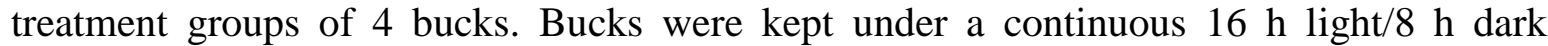
photoperiod and the ambient temperature ranged from 27.3 to $30.3{ }^{\circ} \mathrm{C}$ and relative humidity ranged from 72.8 to $75.4 \%$. The estimated temperature-humidity index value indicated that during the experimental period rabbit bucks were exposed to severe heat stress. Four experimental diets were formulated to represent four dietary treatments. Bucks in the first treatment group were given the basal diet without supplementation and served as a control group, the second group was given $0.5 \%$ MOS in their diet, while the third and fourth groups included bucks with supplementation of 0.1 and $0.2 \%$ bee pollen in their diets, respectively. Results show that addition of $0.2 \%$ bee pollen resulted insignificant decrease in semen hydrogen ion concentration $(\mathrm{pH})$ as compared with the control and the other experimental feed additives. Addition of MOS, 0.1 and $0.2 \%$ bee pollen significantly increased individual sperm motility, beside, these feed additives numerically increased ejaculate volume and sperm concentration as compared with the control group. Administration of $0.2 \%$ bee pollen insignificantly increased live sperm percentage and mass activity by 13.2 and $27.4 \%$, respectively. Numerical increase in packed sperm volume (PSV) percentage amounted to 9.8 $\%$ due to administration of $0.2 \%$ bee pollen. On the other hand, it was observed that MOS and bee pollen improved testosterone concentration and acrosome action percentage in comparison with the control group. Numerical decrease in seminal plasma MDA concentration, with significant increase in seminal plasma TAC due to MOS and bee pollen supplementation in comparison with the control group. In conclusion, results indicated that MOS and bee pollen improved semen quality and antioxidant status of rabbit bucks during Egyptian summer season.
\end{abstract}

Key Words: Rabbits, Mannan oligosaccharide, Bee pollen, Semen quality, Antioxidant status 


\section{INTRODUCTION}

In tropical and sub-tropical areas rabbits are faced with many problems that relate to hot climate, particularly heat stress, which had significant adverse effect on testosterone concentration, ejaculate volume, sperm motility, sperm concentration and semen fructose concentration (Elnagar, 2010). High environmental temperature not only has adverse effects on rabbits' performance but also cause an increase in oxidative stress (Lee, 2002) which can impede disease resistance and impairs antioxidant status (Sabin et al., 2001).

Bees are among the beneficial insects that produce mainly the honey, and also byproducts such as royal jelly, bee wax, propolis and bee pollen (Hascik et al., 2012). Bee pollen contains at least 22 amino acids, 18 vitamins, 25 minerals, 59 trace elements, 11 enzymes or co- enzymes, 14 fatty acids, 11 carbohydrates (35- 61\% glucose, fructose and sucrose) and approximately $25 \%$ protein. Bee pollen is extremely rich in carotenes, which are metabolic precursors of vitamin A. It is also high in B complex and vitamins C, D, E and Lecithin (Sulcerova et al., 2011). Bee pollen has recently received an increased attention for its antibacterial and anti-fungicidal effects (Carpes et al., 2007). Relevant is also the quantity of poly phenolic components, mainly flavonoids (Muradian et al., 2005), that prevent the negative effect of free radicals (Hejinen et al., 2002).

Glycobiology is a relatively new field of study in the world of science. In the past decades, discoveries in the field of glycobiology have revealed the critical role of carbohydrates in the mechanisms of immunity (Dwek, 1996; Munro, 2000; Axford, 2001). These discoveries will lead to the ability to use these functional carbohydrates, with a reduced use of antibiotics, in diets to improve performance and health of animals. Among carbohydrates, mannan oligosaccharide (MOS), derived from the yeast cell wall of Saccharomyces cerevisiae, has been shown to improve animal performance and health through several mechanisms such as prevention of pathogens from binding to the gastrointestinal tract, alteration of gastrointestinal tract microbial populations, and enhancement of immune functions.

Therefore, the objectives of the present study were to verify the effect of using bee pollen and MOS in the feed mixture on semen quality and reduce the effect of lipid peroxidation of $\mathrm{V}$-line rabbit buck semen through Egyptian hot summer season.

\section{MATERIALS AND METHODS}

A total number of 16 mature $\mathrm{V}$ line (VL) rabbit bucks 7-8 months-old of proven fertility with an average initial live body weight of $3.52 \pm 0.32 \mathrm{~kg}$ were classified into four homogeneous treatment groups of 4 bucks. Bucks were kept under a continuous $16 \mathrm{~h}$ light $/ 8 \mathrm{~h}$ dark photoperiod and the ambient temperature ranged from 27.3 to $30.3{ }^{\circ} \mathrm{C}$ and relative humidity ranged from 72.8 to $75.4 \%$. The estimated temperaturehumidity index value indicated that during the experimental period rabbit bucks were exposed to severe heat stress. Animals were housed individually in flat-deck cages and had been trained earlier for semen collection using an artificial vagina. Four experimental diets were formulated to represent four dietary treatments. Bucks in the first treatment group were given the basal diet without supplementation; the second group was given $0.5 \%$ MOS in their diet, while the third and fourth groups included bucks with supplementation of 0.1 and $0.2 \%$ bee pollen in their diets, respectively. All the experimental diets were formulated in such a way to ensure they were both isonitrogenous and isocaloric. The composition and calculated analysis of the basal experimental diet is presented in Table 1. Pellets of the experimental diets were made as follow, pelleting was initiated by molasses addition as binding material and then all diet ingredients were pressed at $70 \mathrm{C}^{\mathrm{o}}$, after that pellets were cooled. The basal experimental diet was formulated to 
cover all essential nutrient requirements for adult male rabbits according to NRC (1977). Bucks were allowed to become accustomed to treatment for a preliminary period of 30 days during June. Semen collection occurred weekly over the 8 weeks during July to August. Feed and water were offered ad libitum throughout the whole experiment. All bucks were kept under similar managerial and environmental condition. Bucks were housed individually in galvanized batteries $(50 \mathrm{Lx} 50 \mathrm{Wx} 40 \mathrm{Hcm})$ provided with feeders and automatic drinkers in a windowed rabbitry. Before starting the experiment, all cages were cleaned and disinfected by fire. The incidence of dangerous diseases was largely avoided and rabbits have never been treated with any kind of systematic vaccination or medication. Urine and faces dropped from cages on the floor were removed every day in the morning.

Semen samples were collected weekly over the 8 weeks using an artificial vagina and the samples of each week were subjected to chemical analysis. Semen collection and handling were carried out and evaluated according to the international guidelines of (IRRG, 2005). Ejaculated volume was measured to the nearest $0.01 \mathrm{ml}$. The volume of each ejaculate was recorded after removal of the gel mass. Immediately after collection, semen was maintained at $37^{\circ} \mathrm{C}$ in a water bath for evaluation. Semen mass motility was given an arbitrary score from 0 to 3 based on the following assessment and the following variables were estimated: $0=$ No current, $(0.5)=$ Very few slow current, 1 $=$ Few slow current, 1.5= Many moderate waves, 2=Many sweeping waves, $2.5=$ Numerous vigorous waves, $3=$ Numerous rapid and vigorous waves, as described by Moule (1965). A weak eosinformalin (10\% formalin) solution was used at a rate of 1: 99 before counting the cells for evaluation of sperm concentration by the improved Neubauer hemocytometer slide method as described by Smith and Mayer (1955).
Individual sperm motility was estimated at 400× magnification (Kamar, 1960). Assessment of live and abnormal spermatozoa was performed using an eosinnigrosin blue-staining mixture (Blom, 1950). Semen $\mathrm{pH}$ was determined just after collection using a $\mathrm{pH}$ cooperative paper ranging from 0 to 14 with 1 grade (Merck KgaA, 64271 Darmstadt, Germany). Serum testosterone was determined by enzyme immunoassay using commercial kits purchased from Biosource. Packed sperm volume (PSV) was recorded using MicroAID® microhematocrit tubes and microhematocrit-centrifuge which were centrifuged for $5 \mathrm{~min}$ at $4000 \mathrm{rpm}$. Evaluation of seminal initial fructose was carried out immediately after collection according to Mann (1948).The acrosome reaction of spermatozoa was analyzed by microscopy in bright-field illumination after staining the smear preparations with naphthol yellow $\mathrm{S}$ and erythrosin according to Bryan and Akruk (1977) with a minor modification. After air-drying, the slides were dipped twice in distilled water to remove the seminal vesicle proteins obscuring the visual assessment of the acrosome reaction. With this method the acrosomal caps in intact spermatozoa stained cherry-pink, whereas sperm heads devoid of acrosomes stained pale yellow. A total of 400 spermatozoa were counted from each slide and the percentages of acrosome reaction-positive (acrosome-reacted) and negative spermatozoa were determined. The acrosome reaction was also checked by phase-contrast microscopy and by transmission electron microscopy (TEM). In phase-contrast microscopy (1000, oil immersion), the spermatozoa with an intact acrosome displayed sharp margins of the head, and after the acrosome reaction the apical regions became fuzzy and the total loss of acrosomes was readily distinguished (Shams-Borhanand Harrison, 1981).

Seminal plasma was separated by centrifugation at $3000 \mathrm{rpm}$ for 20 minutes and was stored at $-20{ }^{\circ} \mathrm{C}$ in Eppendorf tubes 
for further analysis of total antioxidants capacity and malondialdehyde were determined in seminal plasma calorimetrically using commercial kits obtained from (BIO- DIAGNOSTICS, Egypt) according to the procedure outlined by the manufacturer. Data were analyzed as a one-way analysis of variance with semen collection time as replicates using the General Linear Model procedure of SAS (1996). Differences among means were determined using Duncan test (Duncan, 1955).

\section{RESULTS AND DISCUSSIONS}

Results illustrated in Table 2 show the effect of MOS and bee pollen on performance and semen quality.

Results showed insignificant increase in final body weight of buck's fed different feed additives, except the group received diet containing $0.1 \%$ pee pollen final body weight was significantly increased in comparison with the control group. Weight gain was insignificantly affected by different fed additives in comparison with the control group.

Results also show that addition of $0.2 \%$ bee pollen resulted in a numerical decrease in semen hydrogen ion concentration $(\mathrm{pH})$ as compared with the control and the other experimental feed additives. Ejaculate volume of rabbit bucks was numerically increased by addition of MOS, 0.1 and 0.2 $\%$ bee pollen and the increase surpassed the control by 2.5 to $3.8 \%$. Addition of MOS, 0.1 and $0.2 \%$ bee pollen significantly $(\mathrm{P} \leq$ $0.05)$ increased individual sperm motility while, Addition of MOS, 0.1 and $0.2 \%$ bee pollen numerically increased sperm concentration, Shashidhara and Devegowda (2003) reported that sperm density in male Cobb broiler breeders increased in the group given $0.5 \mathrm{~g} / \mathrm{kg}$ MOS in comparison with control. However, there were no differences in proportion of live sperm between the two groups. The results of sperm concentration are in agreement with a previous report in which breeders were fed diets supplemented with a yeast culture (McDaniel and Sefton,
1991). The observed improvement in sperm concentration in the MOS-fed males might have been due to enhanced availability of nutrients facilitated by more efficient nutrient absorption at the level of the gastrointestinal tract. Furthermore, several workers have reported higher antioxidant activity in chickens and piglets fed MOSsupplemented diets (Zhou et al., 1999; Shao et al., 2000). From this perspective, a key aspect that should be deliberated upon is possible improvement in the activity of antioxidants such as glutathione peroxidase (GSH-Px) and improving total antioxidant capacity in MOS-fed bucks and its importance in spermatozoa production and maturation. High levels of GSH-Px are found in the testes, and it acts as a powerful antioxidant in the developing spermatids and spermatozoa (Ursini et al., 1999). Spermatozoa are subject to the damaging effects of high concentrations of peroxides in testes, semen, and utero-vaginal sperm host glands (Lenzi et al., 2000; Surai et al., 2001). In organs such as testes that have high metabolic rates, levels of antioxidants required to ensure survival of spermatozoa in those aerobic environments are high. Thus, high density of spermatozoa recorded in MOS-fed bucks in this trial might have been due to its influence on the antioxidant activity.

Table 2 shows that addition of MOS and 0.1 $\%$ bee pollen resulted in numerical increase in live sperm $\%$ by 4.3 and $6.3 \%$, respectively, also, the aforementioned treatments numerically increased mass activity by 10.5 and $11.1 \%$, respectively, in comparison with the control group free of feed additives. On the other hand, administration of $0.2 \%$ bee pollen significantly $(\mathrm{P} \leq 0.05)$ increased live sperm percentage and mass activity by 13.2 and $27.4 \%$, respectively, as compared with control. In this respect, Selmanoğlu et al. (2009) reported that there were increases in sperm counts and daily sperm production of rats fed with pollen of Raphanusspp. and Cistus spp. Although the increases were not 
significantly different in statistical terms from the control, however, the authors suggested that pollen caused an increase in these parameters. Generally, there is no literature available on pollen effects on sperm counts.

Numerical increase in PSV percentage amounted to $9.8 \%$ due to administration of $0.2 \%$ bee pollen was observed. On the other hand, it was recorded that MOS and bee pollen improved testosterone concentration and acrosome action percentage in comparison with the control group. Selmanoğlu et al. (2009) found that there was an increase in testosterone levels of rats fed with pollen of Raphanusspp. and Cistus spp. Although the increases were not significantly different in statistical terms from the control, however, the authors showed that pollen caused an increase in this parameter. There is rare literature available on pollen effects on testosterone levels.

Data for the effect of MOS and bee pollen on seminal lipid peroxidation are presented in Table 2. Lipid peroxidation, measured as malondialdehyde (MDA), is a free-radical mediated propagation of oxidative insult to polyunsaturated fatty acids involving several types of free radicals (Korkina and Afanas'ev, 1997). Results show a numerical decrease in seminal plasma MDA concentration and significant increase in seminal plasma TAC due to different supplementation used in the present study in comparison with the control group. Mariee et al. (2012) and Al-Rejaie et al. (2013) reported that the hepatic content of MDA was decreased and GSH content was increased by administration of some flavonoids (quercetin and rutin fond in citrus) to rats fed on high-cholesterol diet. A reduction of these enzymes activity is associated with the accumulation of highly reactive free radicals, leading to deleterious effects such as loss of integrity and function of cell membranes when they are present in high concentrations, free radicals are able to interact with the enzymes and inactivate them (Hassan et al., 2011). In contrast, administration of hesperidin in combination with high-cholesterol diet ameliorated the reduction in these parameters resulting in marked elevation in Superoxide dismutase (SOD), catalase (CAT), glutathione peroxidase (GSH-Px) and glutathione-Stransferase (GST), by 49\%, 38\%, $90 \%$ and $53 \%$, respectively, as compared to rats fed HCD alone. These observations have been supported by the finding of Mariee et al. (2012) who reported that the hepatic activities of SOD and CAT were increased by administration of dietary flavonoid quercetin to hypercholesterolemic rats. Recently, Al-Rejaie et al. (2013) demonstrated a significant increase in GSHPx and GST gene expression levels in hypercholesterolemic rats by supplementation with glycosidic flavonoid rutin.

In the study of Akondi et al. (2011), testicular MDA levels were elevated and in diabetic rat group animals and the antioxidant parameters were reduced (SOD and Catalase). Oxidative stress-mediated damage to the sperm plasma membrane, integrity of DNA and on germ cell leads to deterioration of sperm quality (Sani and Noor, 2008; Makker et al., 2009). With the administration of insulin, rutin and naringin alone or in combination, MDA levels were effectively reduced and the SOD increased; Catalase levels comparable with the corresponding normal control value were also achieved. These results suggest that hyperglycemia as stress accompanied by increased free radical formation causes a reduction in endogenous antioxidant capacity, leading to enhanced oxidative stress. Several studies reported the effectiveness of rutin and naringin as antioxidants. Rutin reduces the lipid peroxidation in in-vitro method (Dorozhko et al., 1989). Previous reports suggested that rutin has anti-lipoperoxidation activity by scavenging hydroxyl and superoxide radicals (Negre-Salvayre et al., 1992). Jeon et al. (2002), suggested that naringin reduces the lipid peroxidation in cholesterol fed 
animals by scavenging free radicals that are generated. Ali and El Kader (2004) and Jagetia et al., 2003) reported that naringin reduces the oxidative stress in diabetes mellitus by scavenging free radicals generated by hyperglycemia. In 2006, Jungsook Cho proved that flavonoid hesperidin protects brain by scavenging free radicals.

Techech (2016) who found that addition of 100 and $200 \mathrm{mg} / \mathrm{kg}$ diet of bee pollen to growing rabbits diet decreased the level of blood serum TAC through summer season in comparison with the control rabbits fed diet free of feed additives. This may refer to the strong antioxidant activity of bee pollen. Bee pollen possesses a noticeable source of compounds with health protective potential and antioxidant activity. Results obtained by Attia, et al. (2014) reported that the addition of bee pollen caused a significant increase of total antioxidants capacity as compared to control rabbits.

Vitamin $\mathrm{C}$ and bee pollen have been defined as an important component of an antioxidant network that prevents membrane damage from oxidation (Reed, 1992; Bastos et al., 2004; Le Blanca et al., 2009; Leja et al., 2007). Several investigations on bee pollen have showed that flavonoids concentrated in bee pollen are powerful antioxidants which are capable to scavenge free radicals (Han et al., 2007). It was recorded that antioxidant constituents in bee pollen (including flavonoids and polyphenols) have been reported to increase glutathione content in the liver of laboratory animals (Serra et al., 2001). The elevation of this enzyme by flavonoids may also be responsible for the observed protection against radiationinduced damage (Pham-Huy et al., 2008). By increasing the activities of antioxidant enzymes, flavonoids from bee pollen reduce the number of free radicals or ROS generated and increase the production of molecules protecting against oxidative stress. The increase of antioxidant enzyme activities such as SOD, CAT and GSH may be considered as a protective mechanism against heat-induced free radical production and lipid peroxidation (Tatli Seven et al., 2009). These increases in antioxidant enzyme activities have been considered as a protective response against oxidative stress (Altan et al., 2003). Shahba (2011) demonstrated that plasma total antioxidant capacity (TAC) significantly increased of MOS supplemented-group compared to inulin and $\mathrm{ZnB}$ groups in growing $\mathrm{V}$-line rabbits.

In conclusion, the results indicated that MOS and bee pollen improved semen quality and antioxidant status of rabbit bucks during Egyptian summer season. 
Table (1): Composition and calculated analyses of basal experimental diet

\begin{tabular}{|l|c|}
\hline Ingredients & Experimental diet \% \\
\hline Barley & 20.00 \\
Yellow corn & 14.80 \\
Wheat bran & 10.00 \\
clover hay & 30.20 \\
Soybean meal (44 \%) & 19.60 \\
Molasses & 3.00 \\
Limestone & 1.00 \\
Di-calcium phosphate & 0.30 \\
Salt & 0.50 \\
Vit. And Min. Mix. ${ }^{*}$ & 0.30 \\
Lysine & 0.15 \\
Methionine & 0.15 \\
\hline Total & 100 \\
\hline Chemical Analysis (as fed $\left.{ }^{* *}\right)$ & \\
Crude protein, \% & 17.06 \\
Ether extract, \% & 2.75 \\
Crude fiber, \% & 13.80 \\
Nitrogen free extract, \% & 54.10 \\
Ash, \% & 8.50 \\
Methionine, \% & 0.18 \\
Cystine, \% & 0.24 \\
TSAA, \% & 0.42 \\
DE Kcal / Kg & 2696 \\
\hline
\end{tabular}

*Vitamin/trace mineral premix provides the following (per kg of diet): vitamin A, $1.800 \mathrm{mg}$ retinol; vitamin E, $6.67 \mathrm{mg}$ D-a-tocopherol; menadione, $2.5 \mathrm{mg}$; vitamin D3, 50mg cholecalciferol; riboflavin, $2.5 \mathrm{mg}$; Ca pantothenate, $10 \mathrm{mg}$; nicotinic acid, $12 \mathrm{mg}$; choline chloride, $300 \mathrm{mg}$; vitamin B12, $4 \mathrm{mg}$; vitamin B6, $5 \mathrm{mg}$; thiamine, $3 \mathrm{mg}$; folic acid, $0.50 \mathrm{mg}$; biotin, $0.02 \mathrm{mg}$; $\mathrm{Mn}, 80$ $\mathrm{mg}$; $\mathrm{Fe}, 40 \mathrm{mg}$; $\mathrm{Cu}, 4 \mathrm{mg}$; Se, $0.10 \mathrm{mg}$.

** Calculated according to NRC (1977). 
Table (2): Effect of MOS and bee pollen on body weight, body weight gain and semen quality of V-line bucks

\begin{tabular}{|l|l|l|l|l|}
\hline \multirow{2}{*}{ Traits } & \multirow{2}{*}{ Control } & \multicolumn{3}{|c|}{ Feed additives } \\
\cline { 3 - 5 } & & \multicolumn{2}{|c|}{ MOS } & \multicolumn{2}{c|}{ Bee pollen \% } \\
\cline { 3 - 5 } & & & \multicolumn{1}{|c|}{$\mathbf{0 . 1}$} & \multicolumn{1}{c|}{} \\
\hline & & & & \\
Initial body weight & $3450.1 \pm 335.3$ & $3597.1 \pm 394.2$ & $3822.5 \pm 297.9$ & $3643.7 \pm 219.0$ \\
Final body weight & 3561.2 & 3701.3 & 3924.6 & 3768.8 \\
Body weight gain & $\pm 332.7^{\mathrm{b}}$ & $\pm 379.4^{\mathrm{ab}}$ & $\pm 264.1^{\mathrm{a}}$ & $\pm 110.0^{\mathrm{ab}}$ \\
Semen quality: & $112.37 \pm 11.60$ & $104.12 \pm 12.70$ & $102.12 \pm 9.90$ & $125.00 \pm 13.90$ \\
Hydrogen ion(pH) & & & & \\
Ejaculate volume (ml) & $7.59 \pm 0.40$ & $7.72 \pm 0.30$ & $7.65 \pm 0.20$ & $7.36 \pm 0.20$ \\
Individual motility \% & $0.80 \pm 0.07$ & $0.82 \pm 0.08$ & $0.82 \pm 0.08$ & $0.83 \pm 0.06$ \\
Sperm & $57.17 \pm 3.40^{\mathrm{c}}$ & $61.02 \pm 2.90^{\mathrm{bc}}$ & $62.60 \pm 2.10^{\mathrm{b}}$ & $68.78 \pm 3.10^{\mathrm{a}}$ \\
concentration(10\%/ml) & $170.72 \pm 17.70$ & $194.97 \pm 20.30$ & $207.03 \pm 20.30$ & $198.54 \pm 16.20$ \\
Live sperm\% & $58.63 \pm 2.40$ & $61.25 \pm 3.80$ & $62.35 \pm 4.50$ & $66.35 \pm 4.10$ \\
Mass activity(1-3) & $1.90 \pm 0.30$ & $2.10 \pm 0.40$ & $2.11 \pm 0.50$ & $2.42 \pm 0.20$ \\
Initial fructose(mm/dl) & $251.00 \pm 11.90$ & $272.62 \pm 8.10$ & $268.87 \pm 9.50$ & $269.50 \pm 14.10$ \\
PSV \% & $17.63 \pm 3.70$ & $17.79 \pm 3.20$ & $17.52 \pm 2.60$ & $19.36 \pm 2.60$ \\
Testosterone (ng/dl) & $2.56 \pm 0.50^{\mathrm{c}}$ & $2.84 \pm 0.50^{\mathrm{b}}$ & $3.01 \pm 0.50^{\mathrm{a}}$ & $3.02 \pm 0.60^{\mathrm{a}}$ \\
Acrosome action\% & $51.22 \pm 1.60^{\mathrm{b}}$ & $60.02 \pm 1.50^{\mathrm{a}}$ & $58.90 \pm 1.80^{\mathrm{a}}$ & $58.98 \pm 1.90^{\mathrm{a}}$ \\
& & & & \\
Seminal lipid peroxidation: & & & & \\
\hline Total antioxidant capacity & $1.03 \pm 0.20^{\mathrm{b}}$ & $1.30 \pm 0.20^{\mathrm{a}}$ & $1.25 \pm 0.10^{\mathrm{ab}}$ & $1.38 \pm 0.20^{\mathrm{a}}$ \\
(TAC) mm/L & & & & \\
Malondialdehyde & $6.67 \pm 0.50$ & $5.52 \pm 0.60$ & $5.86 \pm 0.60$ & $5.52 \pm 0.50$ \\
(MDA), (nmol/ml) & & & & \\
\hline
\end{tabular}

${ }^{\mathrm{a}-\mathrm{b}-\mathrm{c}}$ Means within a row having different superscripts are significantly different $(\mathrm{P} \leq 0.05)$.

MOS = mannan oligosaccharide 


\section{REFERENCES}

Akondi, B.R., Challa, S.R., Akula, A. 2011. Protective Effects of Rutin and Naringin in Testicular Ischemia Reperfusion Induced Oxidative Stress in Rats. J. Reprod. Infertil; 12 (3): 209-214. Ali, M. M. and M. A. El Kader 2004. The influence of naringin on the oxidative state of rats with streptozotocin-induced acute hyperglycaemia. $\mathrm{Z}$ Naturforsch $\mathrm{C}$. 59:726-733.

Al-Rejaie, S. S., A. M. Aleisa, M. M. Sayed-Ahmed 2013. Protective effect of rutin on the antioxidant gene expression in hyper cholesterolemic male Westar rat. BMC Complement Altern Med., 12:136. Altan, O., A. Pabuccuoglu, A. Altan, S. Konyalioglu and H. Bayraktar 2003. Effect of heat stress on oxidative stress, lipid peroxidation and some stress parameters in broilers. Br. Poult. Sci. 44:545-550.

Attia, Y. A., El-Hanoun, A. M., Bovera, F., Monastra G., El-Tahawy, W. S. and Habiba, H. I. 2014. Growth performance, carcass quality, biochemical and haematological traits and immune response of growing rabbits as affected by different growth promoters. J. Anim. Physiol. Anim. Nutr., 98: 128-139.

Axford, J. (2001). The impact of glycobiology on medicine. Trends Immunol. 22:237-239.

Bastos, D. H. M., O. M. Barth, C. I. Rocha, I. B. D. Cunha, P. D. Carvalho, E. A. S. Torres and M. Michelan 2004. Fatty acid composition and palynologicalanalusis of bee (Apis) pollen loads in the states of saopaulo and Minas Gerais, Barzil. In Journal of Apicultural Research, vol. 43, 2004, p. 35-39.

Blom, E. 1950. A one-minute live-dead sperm stain by means of Eosin Nigrosin. Fertil. Steril., 1, 176-177.

Bryan, J.H.D. and Akruk, S.R. 1977. A naphthol yellow $S$ and erythrosin staining procedure for use in studies of the acrosome reaction of rabbit spermatozoa. Stain. Technol. 52,47-51.

Carpes, T., R. Begnini, S. Matias de Alencar and M. L. Masson 2007. Study of preparations of bee pollen extracts, antioxidant and antibacterial activity, Ciência e Agrotecnologia31, 1818-1825.

Dorozhko, A. I., A. V. Brodskii, V. A. Kostyuk and A. I. Potapovitch 1989. Chelating and free radical scavenging mechanisms of inhibitory action of Rutin and Qercetin in lipid peroxidation. Biochem. Pharmacol. 38:1763-1769.

Duncan, D. B. 1955. Multiple range and multiple F tests. Biometrics, 11: 1-42.

Dwek, R. A. 1996.Glycobiology: Toward understanding the function of sugars. Chem. Rev. 96:683-720.

Elnagar, Samar, A. 2010. Royal jelly counteracts bucks" summer infertility". Animal Reproduction science, 121: 174180.

Han, X., T. Shen and H. Lou 2007. Dietary Polyphenols and Their Biological Significance. Int.J.Mol.Sci.8: 950-988.

Hascik, P; I. O. E. Elimam; J. Garlik; M, Kacaniova; M, Bobko; V . Knazovicka; K. Vavrisinova; $H$. Arpasova and M. Bobko 2012. Chemical composition of muscle after pollen application in nutrition of broiler chickens. In Potravinarstvo, Vol. 6 (2): 26-32.

Hassan S, S. Abd El-Twab and M. Hetta 2011. Improvement of lipid profile and antioxidant of hypercholesterolemic albino rats by polysaccharides extracted from the green alga Ulva lactuca Linnaeus. Saudi J Biol Sci., 18:333-340

Hejinen, C. G.; R. G. Haenen; M. R. Oostveen; M. E. Stalpers and A .Bast 2002. Protective of flavonoids against lipid peroxidation: the structure activity relationship revisited. Free radic. Res. 36, (5): 575- 581.

IRRG, International Rabbit Reproduction Group. 2005. Guidelines 
for the handling of rabbit bucks and semen. World Rabbit Sci., 13: 71- 91.

Jagetia, G. C., V. A. Venkatesha and T. Koti Reddy 2003. Naringin, a citrus flavonone, protects against radiationinduced chromosome damage in mouse bone marrow. Mutagenesis. 18:337-343. Jeon SM, Bok SH, Jang MK, Kim YH, Nam KT, Jeong TS, Park YB and Choi MS. 2002. Comparison of antioxidant effects of naringin and probucol in cholesterol-fed rabbits. Clin. Chim. Acta.. 317: 181-190

Jungsook Cho. 2006. Antioxidant and neuroprotective effects of hesperidin and its aglyconehesperetin. Archives of Pharmacal Res. 29: 699-706

Kamar, G. A .R. 1960. The influence of semen characteristics on hatching results of chicken eggs. Poultry Science, 39: 188-193.

Korkina, L. G. and I. B. Afanas'ev 1997. Antioxidant and chelating properties of flavonoids. Adv. Pharmacol. 1997, 38, 151-163.

Le Blanca, B., O. Davis, S. Boue, A. De Lucca and T. Deebya 2009. Antioxidant Activity of Sonoran Desert Bee Pollen. Food Chem. 115: 1299-1305.

Lee, C. Y. 2002. Explaining just how vitamin $\mathrm{C}$ works against cancer. The Lancet, 359: 9301-9305.

Leja, M., A. Mareczek, A., G. Wyzgolik, J. Klepacz-Baniak and K. Czekonska 2007. Antioxidative properties of bee pollen in selected plant species. Food Chemistry100 (1): 237240.

Lenzi, A., L. Gandini, M. Picardo, F. Tramer, G.Sandri, and E. Panfili 2000. Lipid peroxidation damage of spermatozoa polyunsaturated fatty acids: scavenger mechanisms and possible scavenger therapies. Front. Biosci. 5:1115.

Makker, K., A. Agarwal and R. Sharma 2009. Oxidative stress and male infertility. Indian J. Med. Res. 129:357367.
Mann, T. 1948. Fructose content and fructolysis in semen. Practical application in the evaluation of semen quality. Journal of Agriculture Science, 38: 323-331.

Mariee, A. D., G. M. Abd-Allah and H. A. El-Beshbishy 2012. Protective effect of dietary flavonoid quercetin against lipemic-oxidative hepatic injury in ypercholesterolemic rats. Pharm Biol., 50(8):1019-1025.

McDaniel, G. R., and T. Sefton 1991. Effect of yeast culture (Yeasacc1026) supplementation on broiler breeders. Poult. Sci. 70(Suppl. 1):172. (Abstr.)

Moule, G. R. 1965. Field investigations with sheep a manual of techniques. (George Russell), 1914-1971.Melb. : C.S.I.R.O., 1965

Munro, S. (2000). Essentials of glycobiology. Trends Cell Biol. 10:552553.

Muradian, L. B; L. C. Pamplona; S. Colmbra and O.M. Berset 2005. Chemical composition and botanical evaluation of dried bee pollen pellets. J. F. Comp. Anal., 18, (1): 105- 111.

Negre-Salvayre, A., A. Affany and C. R. Hariton 1992. Additional antilipoperoxidantactivites of alphatocopherol and ascorbic acid on membrane like systems are potentiated by rutin. Pharmacol. 42:262-272.

NRC 1977. National Research Council. Nutrition requirements of rabbit. The $2^{\text {nd }}$ Edition, National Academy of Science, Washington, D.C.,USA.

Pham-Huy, L., H. He and C. PhamHuy 2008. Free Radicals, Antioxidants in Disease and Health. Int. J. Biomed. Sci.4: 89-96.

Reed, D. 1992. Interaction of vitamin E, ascorbic acid, and glutathione in protection against oxidative damage. In: Packer, L. and Fuchs, J. Editors, Vitamin $\mathrm{E}$ in Health and Disease, Marcel Dekker, New York, 269-281.

Sabin, K., N. Sahin, M. Onderci, S. Yarahoglu and O. Kucuk 2001. 
Protective role of supplemental vitamin E on lipid peroxiddation, vitamins E, A and some mineral concentrations of broilers reared under heat stress. Vet. Med. Czech, 46: 140-144.

Sani, H. A. and M. M. Noor 2008. Effects of Gynuraprocumbens extract and glibenclamide on sperm quality and specific activity of testicular lactate dehydrogenase in streptozotocin induced diabetic rats. Malaysian J. Biochemistry and Molecular biology 16:10-14.

SAS Institute, 1996. SAS ${ }^{\circledR}$ User's Guide: Statistics. SAS Institute Inc., Cary, NC.

Selmanoğlu, G., S. Hayretdağ, D. Kolankaya, A. Ö. Tüylü and K. Sorkun 2009. The effect of pollen on some reproductive parameters of male rats. Pestic. Phytomed.,24:59-63.

Serra, B. J., T. M. Soliva and L. E. Centelles 2001. Evaluation of polyphenolic and flavonoid compounds in honeybee-collected pollen produced in spain. J Agric Food Chem. 49(4):184853.

Shahba H.A.M.A. 2011. Effect of antibiotic and different prebiotic sources on the performance of growing V-line rabbits. Thesis M. Sci., Fac. Agric., Damanhour Univ.

Shams-Borhan, G. and Harrison, R.A.P. 1981. Production, characterisation, and use of onophoreinduced, calcium-dependent acrosome reaction in ram spermatozoa. Garnele Res. 4, 407:132.

Shao L. P., L. J. Zhou, G. P Li, F. P. Lin, Z. F. Fei, T. Jin, Y. Q. Lin, Z. B. Chen, and X. D. Chen 2000. Effects of oral administration of mannanoligosaccharide on immune responses and blood GSH-Px, SOD activities in suckling piglets. Chin. J. Vet. Sci. 20:257-260.

Shashidhara, R. G. and G. Devegowda (2003). Effect of dietary mannan oligosaccharide on broiler breeder production traits and immunity. Poultry Science 82:1319-1325.

Smith. J. T. and D. T. Mayer 1955. Evaluation of sperm concentration by the hemocytometer method. Fertil. Steril., 6: 271-275.

Sulcerova, H.; M. Mihok; M. Juzl and P. Hascik 2011. Effect of addition of pollen and propolise to feeding mixtures during the production of broiler chickens Ross 308 to the color of thigh and breast muscle and $\mathrm{pH}$ determination. Actauniv. agric. et silvic. Mendel. Brun., 2011, LIX, No. 6: 359-366.

Surai, P. F., N. Fujihara, B. K. Speake, J-P. Brillard, G. J. Wishart, and N. H. C. Sparks 2001. Polyunsaturated fatty acids, lipid peroxidation and antioxidant protection in avian semen. Asian-Aust. J. Anim. Sci. 14:1024-1050.

Tatli Seven, P., S. Yılmaz, I. Seven, I. H. Çerçi, M. A. Azman and M. Yılmaz 2009. The effect of propolis on selected blood indicators and antioxidant enzyme activities in broilers under heat stress. Acta Vet Brno, 78, 75-83.

Techech, E. M. M. 2016. Effect of diets containing bee pollen on the performance, carcass, blood parameters, hematological and immunological variables of growing rabbits. MSc. Thesis. Faculty of Agriculture- Saba Basha- Alex Uni.

Ursini, F., S. Heim, M. Kliess, M. Maiorino, A. Roveri, J. Wissing, and L. Flohe 1999. Dual function of the selenoproteinPHGPx during sperm maturation. Science 285:1393-1396.

Zhou, L. J., L. P. Shao, G. P. Li, and F. P. Lin 1999. Effect of mannan oligosaccharide and Streptococcus [Enterococcus] faecalis on the activities of superoxide desmutase (SOD) and glutathione peroxidase (GSH-px) in the blood of chickens and piglets. J. Fujian. Agric. Univ. 28:200-203. 


\section{الملخص العربي}

تأثثر التغذية على حبوب اللقاح والمنان او ليجو سكرايد على جودة السائل المنوي فى الارانب تحت

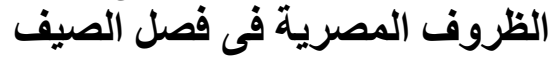

حسن صابر زويل ، سليمان محمد زهران ، محمد حسن عبد الرحيم ، ياسمين مؤمن الجندي ، مجيد محمد جبريل

$$
\text { قسم الانتاج الحيو اني و السمكي كلية الزراعة (سابابانشا ) جامعة الاسكندرية ـ مصر }
$$

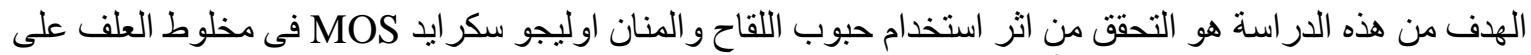

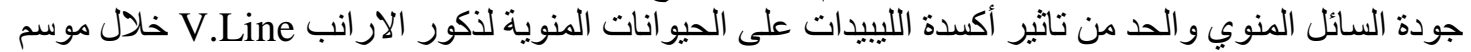

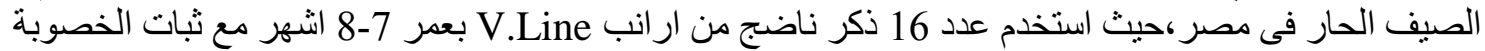

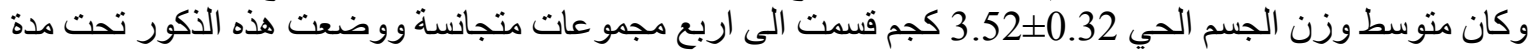

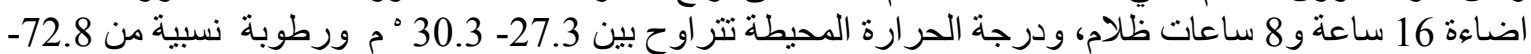

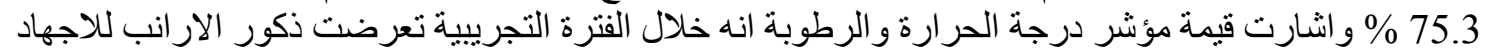

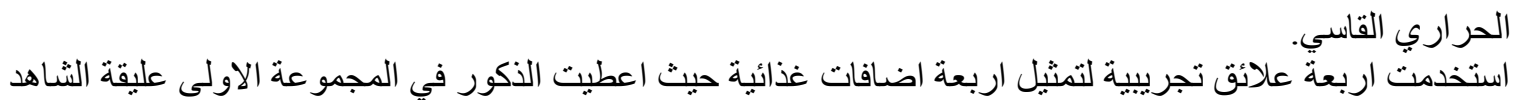

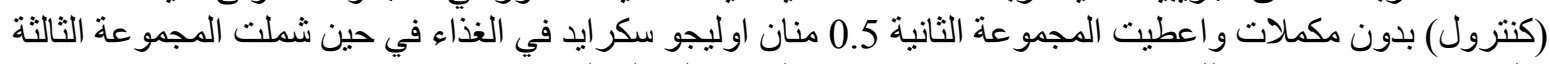

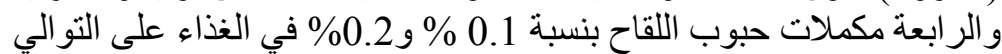

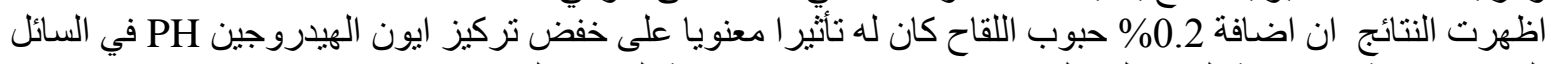

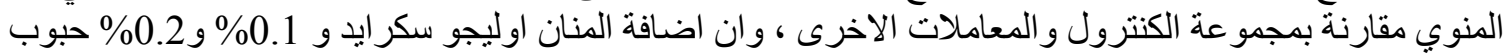

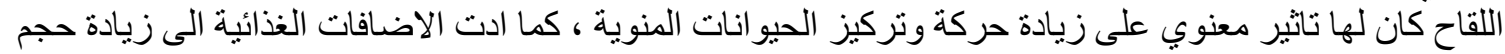
القذفة معنويا مقارنة بمجمو عة الكنترول ، كذللك اضافة 0.2 0.

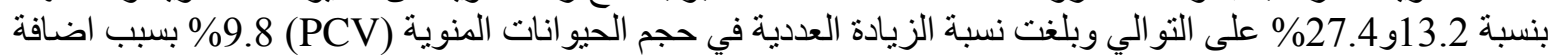

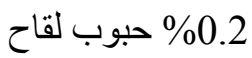

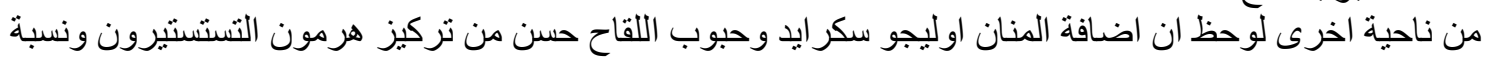

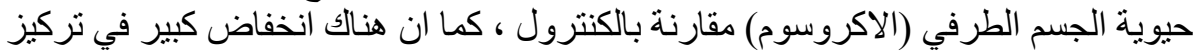

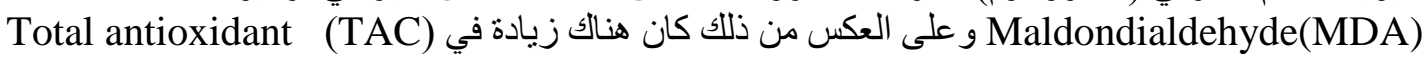
capacity

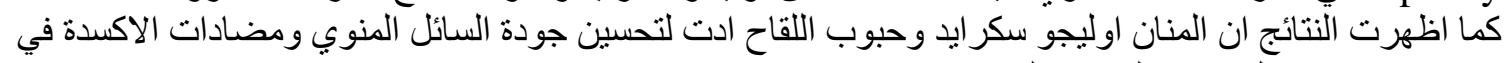

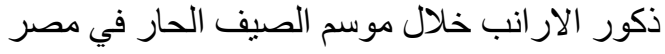

